\title{
Exploring Updates to Performance Evaluation Terminology
}

http://doi.org/10.21272/bel.5(4).6-16.2021

Julie D. Conzelmann, ORCID: https://orcid.org/0000-0003-4333-5532

Associate Professor \& Writing Coach, Jack Welch Management Institute \& College of Business University of Phoenix, Phoenix, Arizona, USA

\begin{abstract}
The goal of this research was to obtain feedback and perspectives from human resource experts regarding the applicability of a newly created performance evaluation document. Reviewed literature includes sources indicating the documentation for employee performance evaluations have not been revised in decades. No recent literature was found regarding updating performance evaluations. Through an exploratory case study, human resource experts helped discern the need to update performance evaluation documents, including the 11 most recognized organizational citizenship behaviors. Purposive and snowball participant selection comprised five qualifying human resources subject matter experts representing healthcare, business, retail, manufacturing, and education from various cities in the United States. Findings revealed the need for organizations to update performance evaluations from the current antiquated and generic documents that only measure basic job-task performance. The outcome was agreement that human resource leaders should update their performance evaluation document to Exhibit B. Results empirically confirmed human resource leaders would support an updated performance evaluation document, substantiating my argument that the newly created performance evaluation document would be beneficial to everyone by fully recognizing and measuring the value of all employee contributions in the workplace.
\end{abstract}

Keywords: Organizational Citizenship Behaviors, Job Performance Assessment, Human Resources, Performance Evaluations, Employee Retention.

JEL Classification: D23, J28, O15.

Cite as: Conzelmann, J.D. (2021). Exploring Updates to Performance Evaluation Terminology. Business Ethics and Leadership, 5(4), 6-16. http://doi.org/10.21272/bel.5(4).6-16.2021.

Received: 11 October 2021

Accepted: 30 November 2021

Published: 30 December 2021

Copyright: (C) 2021 by the author. Licensee Sumy State University, Ukraine. This article is an open access article distributed under the terms and conditions of the Creative Commons Attribution (CC BY) license (https://creativecommons.org/licenses/by/4.0/).

\section{Introduction}

Organizational citizenship behavior is a widely researched topic. With a notable beginning in the 1960s, research increased exponentially over the next 50 years; however, most research focused on person-to-person interactions (Blau, 1964; Conzelmann, 2020a, 2020b; Emerson, 1976). The initial problem was the continued lack of leadership recognition of organizational citizenship behaviors during employee performance evaluations. The current issue extends further to the lack of updated documentation to measure organizational citizenship behaviors, that is, employee contributions that go above and beyond the usual job-related tasks expected of employees (Conzelmann, 2020b). After researching publicly accessible performance evaluation documents and the terminology used for deciding employee rewards and retention, the data revealed a need to update documents used by human resource leaders (Conzelmann, 2020a). As noted in prior research, terminology in performance evaluations is limited to only 11 specific, job-related terms - excluding organizational citizenship behavior terminology.

For this research, I explored human resource leaders' perceptions regarding the inclusion of organizational citizenship behavior terminology in updated performance evaluations. As part of researching this topic, the literature regarding human resources and employee contributions spanned 65 and 100 years. The earliest notable literature included Mayo's realization that human resources must hire, retain, evaluate, recognize, and terminate employees. His inclusion in the Hawthorne studies is how performance evaluations began (Mayo, 1933). Future researchers focused on employee retention, including employee satisfaction, motivation, productivity, and teamwork (Blau, 1964). Subsequent research findings linked employee satisfaction, motivation, productivity, and teamwork to the social exchange theory, substantiating the need for recognition and rewards (Emerson, 1976). In the past decade, researchers added to the literature by linking all employee traits and 
contributions to the success of organizations (Gerpott et al., 2019; He et al., 2019; Lin \& Liu, 2019). While the focus of performance evaluations has been on organizational success, a focus on employee success is necessary. This exploratory research is the first step to add to current relevant literature about evaluating employee contributions, to include organizational citizenship behavior terminology.

The expectation from conducting this exploratory research was to inspire further research and changes to current performance evaluation processes. Another anticipated outcome is that the results might help organizational leaders update performance evaluation terminology by providing feedback regarding current terminology and potential future terminology used in performance evaluations. Therefore, the object of the study was to explore the topic of adding organizational citizenship terminology and how human resource leaders might perceive the addition to provide recognition and rewards. The main benefit of updating performance evaluations for organizations is increasing employee performance, retention, satisfaction, and teamwork. For employees, including organizational citizenship terminology in performance evaluations could mean pay increases, promotions, bonuses, and other benefits awarded by organizational leaders and policies.

\section{Literature Review}

Literature specifically focused on updates and changes to performance evaluation documents was nonexistent. Search terms specific to performance evaluations: Organizational citizenship behaviors, history of human resources, job satisfaction, employee motivation, job productivity, job performance assessment, human resources, performance evaluations, and employee retention, brought forth no existing research regarding updating performance evaluation documents. Samples of performance evaluation documents were readily available, most notably from recent research targeting performance evaluation document terminology (Conzelmann, 2020a; Quantum Workplace, 2020). The following sections comprise the supporting literature for this topic and the first step toward increasing existing literature and knowledge about changes to the performance evaluation process.

The Hawthorne Effect: The Beginning of Human Resources. Going back 100 years, the topic of human relations focused on employee motivation, productivity, and satisfaction, resulting from the outcome of the Hawthorne studies (Mayo, 1933; Openstax, 2018)). Many of the rules of employment came from the research by Mayo, including the "workdays and hours, break times, and incentive plans" (Openstax, 2018: 784). The goal of the experiments in the 1920s and 1930s was to discover how human behavior and relationships affected productivity and motivation. The resultant moniker for the outcome became the Hawthorne effect: "The phenomenon that employees perform better when they feel singled out for attention or feel that management is concerned about their welfare" (Openstax, 2018: 785). During the experiments, employee productivity and motivation increased - merely because the employees were invited to participate in the experiments (Mayo, 1933). Like employee motivation and productivity, as measured using performance evaluations in the $21^{\text {st }}$ century, a statement made during the Hawthorne studies is still applicable in 2021: "Every individual should have the right to feel that he is of economic value to the community" (Mayo, 1933: 194).

Purpose and Relevance of Employee Evaluations. As research evolved over the decades, nothing changed from Mayo's statement about employee value. The social exchange theory, brought forth several decades later, increased organizational leadership's focus on recognizing employees for their job and personal contributions (Blau, 1964). Based on the social exchange theory, organizational citizenship behaviors emerged as an additional contribution by employees, over and above normal job performance expectations (Emerson, 1976). However, continuing research revealed a gap wherein organizational leaders still need to recognize the employees' citizenship contributions. Recognizing employee contributions is an investment in the value obtained from the relationship and outcome of the social exchange. Social exchange means organizations provide employment, and the employees do whatever it takes to meet the organization's goals, mission, and vision (Gerpott et al., 2019; He et al., 2019; Lin \& Liu, 2019).

Recent research supported revising formal performance evaluation documents to include organizational citizenship behavior terms to capture and measure employees' altruistic, over and above, contributions (Conzelmann, 2020a, 2020b). In addition, various sources substantiated that recognition of organizational citizenship behaviors, in addition to the usual job-related tasks, during performance evaluations increases employee satisfaction, job performance, and ongoing exhibition of altruistic and above and beyond contributions (Conzelmann, 2020a, 2020b; Sharma, 2018; Tourigny et al., 2019). However, no new performance evaluations existed measuring both facets of employee contributions. Thus, besides my research on this topic, no literature was available to support my argument that leaders need to recognize organizational citizenship behaviors during performance evaluations. 
As part of the employment process, leaders should provide employees with a list of expected job tasks and goals to meet over certain timeframes. Quarterly, mid-year, and annual performance evaluations are normally expected (Whitlock, 2015). However, some employees may not be performing in the top $20 \%$ or mid-level $70 \%$ - the low-performing $10 \%$ of employees may require a performance improvement program, leading to daily, weekly, or monthly evaluations (Welch \& Welch, 2005). The end goal is to measure the overall performance of employees, to ensure meeting the organizational mission and vision, and performance growth for the employees. Over the years, researchers discussed organizational citizenship behaviors, but until this exploratory research, none has voiced support for change from antiquated evaluations - and bring the performance evaluation process into the $21^{\text {st }}$ century.

Need for Updated Performance Evaluations with Organizational Citizenship Behavior Terminology. Human resource leaders find or create performance evaluation forms based on the overall organizational mission and vision and target specific skills and behaviors expected of employees. Several online websites provide publicly accessible performance evaluations (Quantum Workplace, 2020). In addition, particular organizations use evaluations, and many are generic, available for fair use by any organization. However, with the ease of obtaining literature wherein, leaders agree organizational citizenship behaviors are important to organizational and employee success (Conzelmann, 2020a, 2020b; Gerpott et al., 2019; He et al., 2019; Lin \& Liu, 2019; Sharma, 2018; Tourigny et al., 2019). It was disappointing not to find any updated, publicly accessible performance evaluations. In addition, three years of research have not produced any new or updated publicly accessible performance evaluations that measure employees' expected and intrinsic contributions in organizations. Thus, this exploratory research of a newly created employee performance evaluation document encompassing some of the generic skills and behaviors that organizations expect, including organizational citizenship terminology, was necessary.

\section{Methodology}

Since there was no literature on this specific topic, a qualitative exploratory case study was the appropriate methodology for this research. The exploration process included outreach to a small sample comprising five qualifying human resource experts. The selected individuals were recruited from LinkedIn, among the human resource experts listed in my connections. Only experts in human resource policies and practices whose expertise aligned specifically with measuring the expected employee job tasks and evaluating those behaviors were invited to participate. Inclusion criteria for participation in this research included signing informed consent; volunteering for the exploratory research process and interview voluntarily, without expectations of any form of remuneration or quid pro quo; being 18 years of age or older; having a minimum of a master's degree or higher, with a major or minor in human resources; holding professional in human resources, senior professional in human resources, or Society for Human Resource Management (SHRM) certification; and conducted several employee performance evaluations.

Participants represented organizations and industries from various regions of the United States, including healthcare, business, retail, manufacturing, and education. I manually reviewed all transcripts and extracted pertinent information to explain the review and evaluation of both performance evaluation documents. Exhibit A, while used with permission from the copyright holder, could not be appended, per the copyright holder's agreement with me to use the document only for research (see Appendix A); however, the five qualifying participants did review the document with me during the interview, and the data were extracted for reporting the findings. Additionally, I amended Exhibit B (see Appendix B) while discussing the document with all subject matter experts, as noted in the findings.

\section{Data Collection Process}

At the outset of this research and creating the new performance evaluation, Exhibit B, I ethically recruited someone I knew who works in the human resources profession to meet with me via Zoom to review the document and provide feedback. The meeting lasted about two hours and resulted in permanent changes that helped Exhibit B evolve into the document listed as Appendix B. During this meeting, the individual was asked all the interview questions but only responded to a few of the questions adequately; they kept going off-topic. Therefore, in good faith, I could not ethically use that individual's interview portion of the research for this article. Because the remaining participants offered other changes to Exhibit B during their interviews, all feedback and refinement suggestions from all interviews are incorporated into Exhibit B. Because of the Covid-19 safe distancing requirements, virtual Zoom meetings were used for all interviews between December 1, 2020, and September 1, 2021. Participation in the interview sessions was voluntary, required signing informed consent, took between 30 and 90 minutes, and was scheduled at a convenient time. Interviews were recorded only to 
extract the relevant text from the conversations. Once transcripts were created, the recordings were destroyed. Participants were asked basic demographic questions (see Table 1), followed by a two-step research protocol process and a five-question, open-ended inquiry about their professional perceptions and comparisons of two performance review evaluation documents provided for the interviews, noted as Exhibit A and Exhibit B.

Table 1. Participant Demographics

\begin{tabular}{|c|c|c|c|c|c|c|}
\hline Participant & Gender & Industry & Years & Certification & Age Range & Degree \\
\hline HR1 & Male & Healthcare & $10+$ & PHR & $35-44$ & PhD \\
\hline HR2 & Male & Business & $7-10$ & SHRM & $25-34$ & Masters \\
\hline HR3 & Female & Retail & $7-10$ & SPHR & $45-54$ & Masters \\
\hline HR4 & Female & Education & $10+$ & PHR & $25-34$ & Masters \\
\hline HR5 & Male & Manufacturing & $10+$ & SPHR & $45-54$ & PhD \\
\hline
\end{tabular}

Source: Compiled by the author

Interviews comprised one-on-one discussions related to a review of Exhibit A, created from terms and phrases from 30 random, generic, publicly accessible performance evaluation documents used with permission (Quantum Workplace, 2020). The discussion also included a review of Exhibit B; a performance evaluation document comprised of terms and phrases from previous experience as a human resource leader, eleven terms related to the organizational citizenship behaviors from prior research (Conzelmann, 2020a), and from terms and phrases included in random, generic, publicly accessible performance evaluation documents used with permission (Quantum Workplace, 2020). The newly created instrument measures 15 common job-task expectations blended with the eleven organizational citizenship terms using a 5-point Likert-type scale to measure each section. The subject matter experts did not complete the evaluation but only reviewed the text of the measures for the two documents. Then, they compared the documents per the questions posed and provided feedback and suggested revisions per the two-step research protocol process.

Research Protocol Process. This research focus is leadership recognition of organizational citizenship behaviors, or the lack thereof, regarding employee performance evaluations. Before this point in the research process, I identified terms associated with generic job performance measures (Exhibit A) and organizational citizenship behaviors (Exhibit B) mentioned extensively in recent research. As illustrated in a Venn diagram, where only two terms overlap (see Figure 1), the terminology in older performance evaluations does not match closely with the terminology used in the most recent literature regarding employee performance and organizational citizenship behaviors. For this research study, I intended to gather expert perspectives about updating terminology in performance evaluations to recognize the full scope of employee contributions to organizations. I provided participants with two performance review documents per the following two-step process.

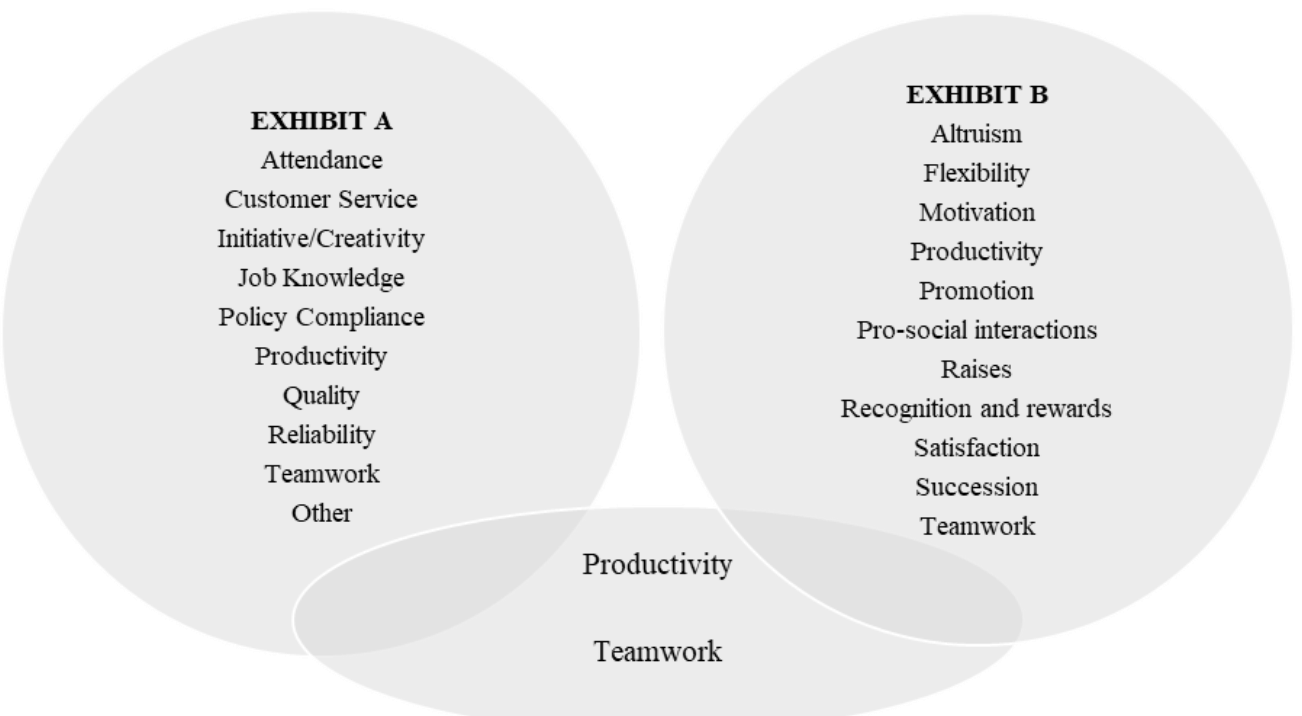

Figure 1. Venn Diagram Illustrating Exhibit A and Exhibit B Terminology and Overlapping Terms

Source: Compiled by the author

In Step 1, I provided each participant a copy of Exhibit A, a random, generic, publicly accessible performance evaluation document comprising the ten most used job performance measures before my research in 2020, as noted in the following list. After allowing participants time to review the document, I asked them to answer several questions that they will use this document to conduct an employee performance evaluation and provide 
me with their expert opinion regarding how this specific performance evaluation document addresses current employee performance. In Step 2, I provided each participant a copy of Exhibit B, a recently created performance evaluation document based on previous research findings comprising the 11 most used terms for exhibiting organizational citizenship behaviors. After allowing participants time to review the document, I asked them to answer several questions from the perspective that they will use this document to conduct an employee performance evaluation and provide me with their expert opinion regarding how this specific performance evaluation document addresses the terms in the list below.

\section{Findings}

\section{Questions and Compilation of Responses}

Question 1. Suppose your organization was currently using Exhibit A for performance evaluations. Do you believe the results would show the full scope of employee contributions compared to using Exhibit B for performance evaluations? The comparison and contrast of the two documents from participants' perspectives did not conclude with the solid approval of one document over the other. All responses to Question 1 aligned with the thoughts of HR3, that Exhibit A measures only specific job-related tasks and excludes other contributions outside the scope of work, given they were using documents like Exhibit A over the past several years. HR1, HR 3, and HR5 believed Exhibit B was a definitive improvement over Exhibit A with respect to increasing the specific behaviors expected for each type of job-task category. However, HR2 and HR4 both saw the value in using either performance evaluation document based on the situational needs of an organization. A specific shared comment was how Exhibit B could help encourage a socially acceptable culture and measure job performance and satisfaction.

Question 2. Which document do you believe is a better measure of employee contributions, such that employees are recognized for going above and beyond while completing the usual and customary job tasks for which they were hired? A specific shared comment among participants was how Exhibit B could help encourage a socially acceptable culture and inspire employees to go above and beyond the expected job tasks for which they are hired. All participants stated that Exhibit A provides a clear guide for measuring employee performance based on generic tasks: coming to work on time, doing the job well, and meeting timeline goals; but they also noted the document is quite familiar and closely matches the performance evaluation documents they use currently.

Question 3. If your boss were to conduct your performance evaluation today, which document do you believe would better measure your contributions as an employee? Asking Question 3 and adding prompts of using either Exhibit A or Exhibit B, and why, participants unanimously selected Exhibit B. The reasons given included Exhibit B is more detailed; the prompts provide more opportunities to acknowledge individual behaviors. For example, HR1 mentioned several reasons Exhibit B would be the preferred performance evaluation document: measuring organizational citizenship behaviors helps meet the organizational mission and vision, increases employee performance and satisfaction, and inspires employees to set personal goals toward success, and from that success, the organization also benefits.

Question 4. Take a moment to reflect upon Exhibit A as the document used in your current organization for employee evaluations. Then, if given the opportunity, would you support a change from Exhibit A to Exhibit B? Four participants said they would support the implementation of Exhibit B for performance evaluations if they were the decision-maker for the change. HR3 was less sure of the change, given that the retail industry does not provide such close observation of employees by leadership. However, when suggesting Exhibit B could be an internal human resource leadership document or used as an internal employee self-assessment document, HR1 added that Exhibit B could also be valid for both measures.

Question 5. Do you have anything you would like to add about Exhibit A, Exhibit B, or both? HR1 believed that human resource and organizational leaders must consider changing from the antiquated performance evaluation documents, some as much as 10 to 20 years old, or more. Consideration for current times, the $21^{\text {st }}$ century, requires rethinking how leaders measure and reward employee job performance. A poignant comment from HR1 was,

I think people really need that [pat's self on the back], especially now with Covid, how we're all, you know, working the way that we are [remotely]. We really need to let people know that not only are they growing and getting the job done, but that we also like and appreciate what they have going on with their daily performance.

He added a comment that he would like a copy of Exhibit B to propose a change in documents in his organization. HR2 was forward-thinking and believed Exhibit B could be valuable for daily, weekly, monthly, 
or quarterly employee self-evaluations, in addition to annual management-level evaluations. Another facet noted about Exhibit B is that teams have specific benchmarks or milestones to use the document to evaluate the groups' progress. However, he said, "This document may have a farther reach than some of the usual, management-level, short-sighted expectations, by not labeling the document with a timeline for use." He also added that he would like a copy of Exhibit B to propose a change in documents in his organization.

HR3 explained that using Exhibit B could provide an avenue for organizational leaders to acknowledge employee altruism. For example, if she were to use Exhibit B for employee evaluations, "the give back to employees, over title or pay increases, would be affecting change by creating a wonderful work environment. I mean, human resources leaders could learn a lot from using this performance evaluation document, too." She also added that she would like a copy of Exhibit B to propose a change in documents in her organization. HR4 has been involved in education for 20 years with the same school district. When reviewing Exhibit A, she commented how closely the terminology related to the district's current performance evaluation document, calling the document "bland" and "outdated." In the present time of Covid, all performance evaluations occur during virtual meetings and have made the performance evaluation process far more impersonal. HR4 stated,

We need to let teachers know that we see all the things they do to make virtual and classroom learning success, and we should also talk to them about how awesome they are all the time. Exhibit B is great! It provides so much in-depth focus on what our teachers are doing - and not just teaching - but taking books and supplies to children's homes or ensuring the kids have their support when they get stuck - that is above and beyond! When we, as educational leaders, provide an in-depth evaluation to our teachers and staff, we can work together to decide what's next, make goals, and visualize what and who we aspire to become. We must find a way to recognize the contributions our teachers make fully - and Exhibit B would be my choice if I were able to implement that as our performance evaluation document.

HR5 works in the manufacturing industry, supervising 300 employees. His first comment when reviewing Exhibit A was, "This is not much to guide employees to meet organizational goals!" While reviewing Exhibit B, HR5 provided suggestions for changes to the document (a misspelled word). As I made that change, he said,

In my line of work, I have to be aware of employees who are doing a great job and employees who are not doing so well but could use some inspiration and encouragement to level up. I recently held mid-year performance evaluations using our current [performance evaluation] document. After seeing Exhibit B, I could see some topics that would have been excellent measures for our struggling employees to strive for. I noticed the people who were my rock stars, who came in on time, took their breaks on time, left on time, asked for extra work, and tried to help their colleagues. So, I started thinking about it - using Exhibit A, I mean. I would feel unappreciated just being asked about those generic job tasks. I would implement this performance evaluation [Exhibit B] in a hot minute! It is how I would want to be evaluated for the hard work I do for my organization.

\section{Discussion}

Five qualifying subject matter experts in human resources agreed that organizations should use the newly created and reviewed performance evaluation document, Exhibit B, to measure employees' basic job-task performance and organizational citizenship behaviors. When asked if they believed employee satisfaction and performance would increase if they were evaluated using the newly created performance evaluation document provided as Exhibit B, two participants thought that both types of performance evaluations have their place, depending on organizational need.

This exploratory research follows my previous research regarding leadership recognition of organizational citizenship behaviors in performance evaluations. My initial argument was that organizational leaders do not formally recognize the altruistic and intrinsic behaviors individuals exhibit while performing the expected job tasks for which they were hired (Conzelmann, 2020a, 2020b; Gerpott et al., 2019; He et al., 2019; Lin \& Liu, 2019; Sharma, 2018; Tourigny et al., 2019). Building upon the findings from these previous studies, I conducted a word search using 30 publicly accessible, generic performance evaluations and peer-reviewed journal articles (Quantum Workplace, 2020). While the generic performance evaluations had ten recurring terms, only two (productivity and teamwork) matched the 11 recurring terms relating to organizational citizenship behaviors listed in the peer-reviewed articles (Conzelmann, 2020a). From these findings, I created a performance evaluation document, Exhibit B. After their assessment, all five subject matter experts in human resources agreed that Exhibt B would be the most useful performance evaluation document. They noted the ease of measuring and recognizing all employee contributions. Therefore, both the expected job-related tasks and 
altruistic contributions will be noteed toward enhancing organizational and personal success. Additionally, while the most notable use of performance evaluations is annual, Exhibit B can be used daily, weekly, monthly, quarterly, semi-annually, or annually; and for individual, team, and leadership evaluations, as noted by HR2 and Whitley (2015).

It is time to disrupt the way things have always been done and begin recognizing all contributions of employee job performance. Organizational leaders need to recognize the varied dimensions of employees' expected job tasks and unexpected altruistic and intrinsic contributions and provide commensurate with the job well done. Therefore, my recommendation for future research is to test the newly created Exhibit B, Performance Evaluation Inclusive of Organizational Citizenship Behaviors, against an organization's current performance evaluation. The goal is to test the hypothesis that employee satisfaction and performance will increase when employers use Exhibit B for performance evaluations. The benefit to the organization is increased focus on productivity and success by measuring employees' altruistic and intrinsic attributes. The advantage to employees is increased rewards and recognition for job performance above and beyond regular job tasks.

Funding. There is no funding for this research.

Acknowledgements. My deepest thanks to the individual who provided excellent feedback and suggestions to help revise Exhibit B and the five qualifying human resource leaders for participating fully in this research. A special note of appreciation goes to Quantum Workplace [online] for permission to use performance evaluation materials. Additional support from several colleagues who helped get this article to publication. I also wish to acknowledge my husband, Eric Conzelmann, for his loving support during my writing and academic endeavors.

\section{References}

1. Blau, P.M. (1964). Exchange and power in social life. Wiley. 352 p. [Google Scholar]

2. Conzelmann, J.D. (2020a). Document review: Journal articles, performance evaluations, and organizational citizenship terminology. Business Ethics and Leadership, 4(2), 75-85. [Google Scholar] [CrossRef]

3. Conzelmann, J.D. (2020b). Leaders recognizing and rewarding organizational citizenship behaviors during formal employee performance evaluations. e-Journal of Social \& Behavioural Research in Business, 11(1), 21-38. [Google Scholar]

4. Emerson, R.M. (1976). Social exchange theory. Annual Review of Sociology, 2(1), 335-362. [Google Scholar] [CrossRef]

5. Gerpott, F., Quaquebeke, N.V., Schlamp, S., \& Voelpel, S.C. (2019). An Identity perspective on ethical leadership to explain organizational citizenship behavior: The interplay of follower moral identity and leader group prototypicality. Journal of Business Ethics, 156, 1063-1078. [Google Scholar] [CrossRef]

6. He, P., Peng, Z., Zhao, H., \& Estay, C. (2019). How and when compulsory citizenship behavior leads to employee silence: A moderated mediation model based on moral disengagement and supervisor subordinate guanxi views. Journal of Business Ethics, 155, 259-274. [Google Scholar] [CrossRef]

7. Lin, Y., \& Liu, N. (2019). Corporate citizenship and employee outcomes: Does a high-commitment work system matter? Journal of Business Ethics, 156, 1079-1097. [Google Scholar] [CrossRef]

8. Mayo, E. (1933). The human problems of an industrial civilization. The Macmillan Co. 204 p. Available at: [Link]

9. Openstax. (2018). Introduction to Business. In Gitman, L.J., McDaniel, Shah, A., Reece, M., Koffel, L., Talsma, B., \& Hyatt, J.C., Introduction to Business. Available at: [Link]

10.Quantum Workplace (2020). Future of work: 17 performance review templates to motivate employees. Available at: [Link]

11.Sharma, D. (2018). When fairness is not enough: Impact of corporate ethical values on organizational citizenship behaviors and worker alienation. Journal of Business Ethics 150, 57-68. [Google Scholar] [CrossRef]

12.Tourigny, L., Han, J., Baba, V.V., \& Pan, P. (2019). Ethical leadership and corporate social responsibility in China: A multilevel study of their effects on trust and organizational citizenship behavior. Journal of Business Ethics, 158, 427-440. [Google Scholar] [CrossRef]

13.Welch, J., \& Welch, S. (2005). Winning. Harper Collins Publishers. 384 p. Available at: [Link]

14. Whitlock, T. (2015). The history of performance reviews and the future of employee evaluations. [Blog] Stanford for Success. Available at: [Link] 
Appendix A

\section{Permission to Use Publicly Accessible Performance Evaluations for Research Purposes}

Good afternoon!

My name is Julie Conzelmann, and I am writing an article about leaders recognizing organizational citizenship behaviors in formal performance review processes. This article is not required for any specific job or educational need, but only about a topic of which I have a great passion!

My methodology is a descriptive document analysis; meaning, the research focus is solely on the inclusion or exclusion of certain words in publicly obtainable performance evaluation documents. Completion of my article requires a word association analysis from as few as 10 but as many as 50 publicly accessibly sample performance review documents.

Your website www.quantumworkplace.com has several publicly accessible and free sample performance review evaluations for immediate download and free of charge. Your terms of service state the documents, although publicly accessible, are still covered under intellectual property rights, and thus, I am requesting permission to use the aforementioned documents as part of my document analysis.

I will provide credit to Quantum Workplace for use of any documents used in the study; however, no specific documents will be identified in the analysis or report of findings. Words, either included or excluded, are the only terms used for reporting the findings, with citations to Quantum Workplace, where applicable, when mentioning where generic forms for review may have been obtained. None of the documents used will be published or used for any monetary gain on my part, but only for a document and word analysis process to reveal the results of my research.

If you are agreeable to my request, all you need do is reply to this inquiry with a statement that permission is granted, and any other caveats required and not mentioned in my request above. I appreciate your consideration and am happy to answer any questions you might have about my request.

Respectfully,

Julie Conzelmann

Response to me:

Hi Julie,

Yes, you may use our resources as part of your document analysis.

Thanks for reaching out! 


\section{Performance Evaluation Inclusive of Organizational Citizenship Behaviors}

\begin{tabular}{|c|c|c|c|c|c|c|c|}
\hline & Metric & Never & Occasionally & Sometimes & Most of the Time & Always & No Experience \\
\hline \multirow[t]{2}{*}{1} & Behaves consistently with the company's mission, vision and values & 1 & 2 & 3 & 4 & 5 & $\mathrm{NE}$ \\
\hline & $\begin{array}{l}\text { Supports and respects diversity } \\
\text { Supports organization's goals and values }\end{array}$ & & & & & & \\
\hline \multirow[t]{2}{*}{2} & Recognized as a person of integrity by co-workers & 1 & 2 & 3 & 4 & 5 & NE \\
\hline & $\begin{array}{l}\text { Demonstrates integrity and ethics } \\
\text { Demonstrates respect for all others } \\
\text { Demonstrates commitment to diversity and inclusion/pluralism }\end{array}$ & & & & & & \\
\hline \multirow[t]{2}{*}{3} & Participates well in a team environment & 1 & 2 & 3 & 4 & 5 & $\mathrm{NE}$ \\
\hline & $\begin{array}{l}\text { Has an altruistic attitude of helpfulness toward co-workers. Demonstrates } \\
\text { teamwork and collaboration } \\
\text { Motivates and encourages others }\end{array}$ & & & & & & \\
\hline \multirow[t]{2}{*}{4} & Complies with company policies and procedures & 1 & 2 & 3 & 4 & 5 & $\mathrm{NE}$ \\
\hline & $\begin{array}{l}\text { Completes administrative tasks correctly and on time } \\
\text { Follows policies and procedures }\end{array}$ & & & & & & \\
\hline \multirow[t]{2}{*}{5} & $\begin{array}{l}\text { Demonstrates professionalism and courtesy when communicating with } \\
\text { coworkers }\end{array}$ & 1 & 2 & 3 & 4 & 5 & NE \\
\hline & $\begin{array}{l}\text { Expresses ideas and thoughts well verbally } \\
\text { Expresses ideas and thoughts well in written form } \\
\text { Exhibits good listening and comprehension } \\
\text { Keeps others adequately informed } \\
\text { Selects and uses appropriate communication methods }\end{array}$ & & & & & & \\
\hline \multirow[t]{2}{*}{6} & $\begin{array}{l}\text { Represents the company in a positive manner with internal and external } \\
\text { customers }\end{array}$ & 1 & 2 & 3 & 4 & 5 & NE \\
\hline & $\begin{array}{l}\text { Establishes and maintains effective relationships } \\
\text { Exhibits tact and consideration } \\
\text { Displays positive outlook and pleasant manner } \\
\text { Responds to requests for service and assistance } \\
\end{array}$ & & & & & & \\
\hline \multirow[t]{2}{*}{7} & Continues to develop new skills and to grow as a professional & 1 & 2 & 3 & 4 & 5 & $\mathrm{NE}$ \\
\hline & $\begin{array}{l}\text { Demonstrates innovation and flexibility } \\
\text { Demonstrates professional development } \\
\text { Seeks increased responsibilities } \\
\text { Undertakes self-development activities } \\
\text { Indicates a desire to meet organizational succession goals }\end{array}$ & & & & & & \\
\hline 8 & Productivity & 1 & 2 & 3 & 4 & 5 & $\mathrm{NE}$ \\
\hline$* *$ & $\begin{array}{l}\text { Supports accuracy and thoroughness in a productive manner } \\
\text { Completes tasks and responsibilities in an appropriate and timely manner } \\
\text { Manages competing demands } \\
\text { Changes approach or method to best fit the situation } \\
\text { Commits to doing the best job possible }\end{array}$ & & & & & & \\
\hline
\end{tabular}


Performance Evaluation Inclusive of Organizational Citizenship Behaviors

\begin{tabular}{|c|c|c|c|c|c|c|c|}
\hline 9 & Respectful & 1 & 2 & 3 & 4 & 5 & $\mathrm{NE}$ \\
\hline & $\begin{array}{l}\text { Works well in group problem solving situations } \\
\text { Adapts to changes in the work environment }\end{array}$ & & & & & & \\
\hline \multirow[t]{2}{*}{10} & Punctual & 1 & 2 & 3 & 4 & 5 & $\mathrm{NE}$ \\
\hline & $\begin{array}{l}\text { Schedules time off in advance in collaboration with team goals } \\
\text { Begins working on time } \\
\text { Keeps absences within guidelines } \\
\text { Ensures work responsibilities are covered when absent } \\
\text { Arrives at meetings and appointments on time }\end{array}$ & & & & & & \\
\hline \multirow[t]{2}{*}{11} & Accepts responsibility for their own actions & 1 & 2 & 3 & 4 & 5 & $\mathrm{NE}$ \\
\hline & $\begin{array}{l}\text { Monitors own work to ensure quality } \\
\text { Asks for help when needed }\end{array}$ & & & & & & \\
\hline \multirow[t]{2}{*}{12} & Works efficiently & 1 & 2 & 3 & 4 & 5 & $\mathrm{NE}$ \\
\hline & $\begin{array}{l}\text { Prioritizes work well } \\
\text { Displays commitment to excellence } \\
\text { Identifies problems in a timely manner } \\
\text { Gathers and analyzes information skillfully } \\
\text { Develops alternative solutions } \\
\text { Resolves problems in early stages } \\
\text { Offers assistance and support to co-workers } \\
\text { Works cooperatively in group situations } \\
\text { Works actively to resolve conflicts }\end{array}$ & & & & & & \\
\hline \multirow[t]{2}{*}{13} & Communication Skills & 1 & 2 & 3 & 4 & 5 & $\mathrm{NE}$ \\
\hline & $\begin{array}{l}\text { Willing to take direction from management and coleagues from all levels } \\
\text { Listens to what others have to say and acts toward meeting goals } \\
\text { Applies feedback to improve performance } \\
\text { Accepts instruction and/or constructive feedback }\end{array}$ & & & & & & \\
\hline \multirow[t]{2}{*}{14} & Job Knowledge & 1 & 2 & 3 & 4 & 5 & $\mathrm{NE}$ \\
\hline & $\begin{array}{l}\text { Competency in required job skills and knowledge Exhibits ability to learn } \\
\text { and apply new skills and apply them in their role } \\
\text { Keeps appraised of current developments } \\
\text { Requires minimal supervision and is coachable } \\
\text { Displays understanding of how job relates to other departments } \\
\text { Uses resources effectively }\end{array}$ & & & & & & \\
\hline \multirow[t]{2}{*}{15} & Organizational Citizenship Behaviors & 1 & 2 & 3 & 4 & 5 & $\mathrm{NE}$ \\
\hline & $\begin{array}{l}\text { Looks for and takes advantage of opportunities to contribute toward } \\
\text { departmental goals } \\
\text { Exhibits altruistic behaviors: selfless acts of helpfulness, such as } \\
\text { volunteering } \\
\text { Encourages an empathetic, resilient, and pro-social work culture } \\
\text { Expresses satisfaction with job } \\
\text { Expresses desire for promotional opportunities }\end{array}$ & & & & & & \\
\hline
\end{tabular}




\section{Performance Evaluation Inclusive of Organizational Citizenship Behaviors}

Employee Evaluation Rating:

1. Total Score Achievable:

$\underline{75} \quad \underline{100} \%$

2. Total Score Earned:

3. Final Percentage: [Total score in 2 divided by 75]

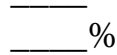

Target Rating for Next Evaluation: $\%$

Future Employee Goals:

Additional Comments:

Source: Compiled by the author 